\title{
Second Primary Tumours of the Head and Neck are not Associated with Adverse Overall Survival in Oral Squamous Cell Carcinomas
}

Rostam Dariush Farhadieh*, Petr Otahal, Kiarash Taghavi, Arash Salardini, Pamela Russell and Robert Smee

St Vincent's Hospital Melbourne, Victoria Australia

\begin{abstract}
Objective: Second primary tumours (SPT) have been implicated in the dismal overall survival (OS) of head and neck Squamous cell carcinomas (HNSCC). The incidence of SPT, the SPT diagnostic time-lag and the impact on OS were assessed.

Subjects and methods: 363 consecutive patients treated for primary oral SCCs (1967-2004) were analyzed retrospectively in this study. $95.1 \%$ and $90.5 \%$ of patients reached a minimum follow-up period of 3 and 5 years respectively.

Results: Of 363 patients; $68(18.7 \%)$ were diagnosed with metachronous SPT, 49 (13.5\%) developed upper aerodigestive tract (UAD)-SPT, 28 (7.7\%) were diagnosed with HNSCC-SPT, and $21(5.8 \%)$ developed lung or esophageal carcinoma. Patients with subsequent HNSCC-SPT had a better median survival during follow-up than those not diagnosed with SPTs $(p=0.0018)$. The rate of mortality in these patients showed a substantial increase compared to patients with no subsequent SPT Diagnosis after 144 months. After 200 months the survival experience was no better than those without SPT.
\end{abstract}

Conclusion: These results suggest a better OS for patients afflicted with HNSCC-SPT. This also reflects that at least some of the noted improved OS of HNSCC-SPT patients is due to temporally cumulated risk associated with developing SPT.

Keywords: Oral squamous cell carcinoma; Second primary tumours; Prognosis; Overall survival

\section{Introduction}

Head and neck squamous cell carcinoma (HNSCC) incidence, morbidity and mortality remain a serious public health issue. Despite relatively early diagnosis, treatment and accessible anatomical surveillance, oral squamous cell carcinoma (OSCC) continues to have poor outcomes including poor overall survival (OS) [1]. Second primary tumours (SPT), a well established phenomenon in HNSCC, are universally considered to be a poor prognostic indicator for OS. Reports of SPT incidence vary from 2-30\% [2-6]. These involve the upper aerodigestive (UAD) tract as well as remote sites.

The field cancerisation theory first put forward by Slaughter asserts that repeated exposure of the UAD mucosa to carcinogens, chiefly tobacco and alcohol, result in independent neoplastic tissues along the tract that are separated by site and time [7]. Many previous reports have either lacked adequate follow-up or have suffered from inconsistencies in diagnostic criteria and patient selection [8].

The aim of this study was, first to establish the incidence and risk of developing UAD-SPT in patients diagnosed with OSCC and second, to appraise the OS rates of patients with SPT in this cohort.

\section{Materials and Methods}

\section{Patients}

A single center retrospective analysis of 371 patients treated for primary OSCC at Prince of Wales Hospital Department of Radiation Oncology (1967-2007) was undertaken. To ensure a minimal threeyear follow-up, only patients commencing treatment for their primary OSCC between 1967 and 2004 were used in this study. Ethics approval was obtained in accordance with the National Health and Medical Research Council from the South-East Area Health Service Ethics Committee. All regular patient follow-up was undertaken at Prince of
Wales Multi-disciplinary Outpatient Radiation Oncology clinics.

Diagnosis of SPTS were based on the Warren and Gates criteria: [9]

1. Each lesion is distinct and separated by normal tissue

2. The possibility of metastasis is excluded

3. Histological documentation of each malignancy at the time of diagnosis

The patient cohort was divided into two broad groups: those with a subsequent diagnosis of SPT and those free from SPT during follow-up. Five patients were diagnosed with synchronous SPT (within 6 months of the primary OSCC), and three patients were missing information on the time of SPT occurrence. After excluding these cases 363 patients remained to be studied. The total patients lost during follow-up were, $18(5.0 \%)$ and $37(10.2 \%)$ at three and five years respectively. Patients diagnosed with SPT were further stratified into those occurring in the UAD-SPT (either HNSCC or lung/oesaphageal), and those that occurred elsewhere (Remote-SPT). Lung lesions were designated SPT only if solitary and histologically distinct from the index tumour.

*Corresponding author: Rostam Dariush Farhadieh, MD, MRCS, St Vincent's Hospital Melbourne, Victoria Australia, E-mail: wnolker@hotmail.com, rostam74@ yahoo.com

Received October 25, 2010; Accepted December 11, 2010; Published December 15,2010

Citation: Farhadieh RD, Otahal P, Taghavi K, Salardini A, Russell P, Smee R (2011) Second Primary Tumours of the Head and Neck are not Associated with Adverse Overall Survival in Oral Squamous Cell Carcinomas. J Cancer Sci Ther 3 : 030-034. doi:10.4172/1948-5956.1000053

Copyright: (C) 2011 Farhadieh RD, et al. This is an open-access article distributed under the terms of the Creative Commons Attribution License, which permits unrestricted use, distribution, and reproduction in any medium, provided the original author and source are credited. 
Citation: Farhadieh RD, Otahal P, Taghavi K, Salardini A, Russell P, Smee R (2011) Second Primary Tumours of the Head and Neck are not Associated with Adverse Overall Survival in Oral Squamous Cell Carcinomas. J Cancer Sci Ther 3: 030-034. doi:10.4172/1948-5956.1000053

At diagnosis and treatment of primary OSCC, a number of clinical parameters were recorded, including age, tumour stage, nodal stage, clinical stage, and treatment mode. Following treatment of the primary tumour any local or nodal recurrence was noted. Local recurrence was defined as a lesion growing at the primary tumour site, not separated by any normal tissue, with histological findings supporting recurrence. Mortality was recorded to the nearest month and information on HNSCC specific death was also available. Clinical parameters of the patient cohort are presented in Table 1.

\section{Statistical analysis}

Stata 10.1 was used for all statistical analysis. Initially patient characteristics were assessed across the SPT subgroups using a Pearson Chi-Squared test. For groups with small expected cell frequencies, the Fisher Exact Test was used but there was little difference from the Chi-squared test and so it is not reported. Due to the small number of oesophageal SPT, this subgroup was combined with the lung SPT subgroup.

Time to SPT occurrence and OS were assessed for different patient groups using log-rank and Wilcoxon tests. Further analysis was carried using Cox's proportional hazard model to compare the survival of HNSCC-SPT against no SPT patients after adjustment for recurrence.

\section{Results}

\section{Patient characteristics}

Three-hundred and sixty-three patients diagnosed and treated for primary OSCC were included in this study. During a median followup period of 44 months (range 0-314 months), 68 (18.7\%) developed metachronous SPT. The majority of these $(49,13.5 \%)$ were UAD-SPT. The HNSCC-SPT were dominant at 28 (7.7\%), followed by lung at 18 $(5.0 \%)$ and a small number ( 3 or $0.8 \%$ ) of oesophageal malignancies.

\begin{tabular}{|c|c|c|c|c|c|}
\hline \multirow[b]{2}{*}{ Clinical Parameters } & \multicolumn{4}{|c|}{ Second Primary Tumor Status } & \multirow[b]{2}{*}{$p$-value* } \\
\hline & None & HNSCC & Lung/ Oesophagus & Remote & \\
\hline \multicolumn{6}{|l|}{ Age } \\
\hline$<65$ & $172(81 \%)$ & $18(8 \%)$ & $9(4 \%)$ & $14(7 \%)$ & \multirow{2}{*}{0.230} \\
\hline$\geq 65$ & $123(82 \%)$ & $10(7 \%)$ & $12(8 \%)$ & $5(3 \%)$ & \\
\hline \multicolumn{6}{|l|}{ Sex } \\
\hline Male & $188(80 \%)$ & $22(9 \%)$ & $14(6 \%)$ & $11(5 \%)$ & \multirow{2}{*}{0.086} \\
\hline Female & $107(84 \%)$ & $6(5 \%)$ & $7(5 \%)$ & $8(6 \%)$ & \\
\hline \multicolumn{6}{|l|}{ Index Tumour Stage† } \\
\hline 1 & $87(85 \%)$ & $5(5 \%)$ & $6(6 \%)$ & $4(4 \%)$ & \multirow{4}{*}{0.784} \\
\hline 2 & $123(79 \%)$ & $16(10 \%)$ & $9(6 \%)$ & $7(5 \%)$ & \\
\hline 3 & $62(82 \%)$ & $4(5 \%)$ & $4(5 \%)$ & $6(8 \%)$ & \\
\hline 4 & $21(75 \%)$ & $3(11 \%)$ & $2(7 \%)$ & $2(7 \%)$ & \\
\hline \multicolumn{6}{|l|}{ Index Nodal Stage } \\
\hline 0 & $206(81 \%)$ & $22(9 \%)$ & $14(5 \%)$ & $13(5 \%)$ & \multirow{4}{*}{0.197} \\
\hline 1 & $47(80 \%)$ & $6(10 \%)$ & $1(2 \%)$ & $5(8 \%)$ & \\
\hline 2 & $40(85 \%)$ & $0(0 \%)$ & $6(13 \%)$ & $1(2 \%)$ & \\
\hline 3 & $2(100 \%)$ & $0(0 \%)$ & $0(0 \%)$ & $0(0 \%)$ & \\
\hline \multicolumn{6}{|l|}{ Index Clinical Stage† } \\
\hline 1 & $76(85 \%)$ & $5(6 \%)$ & $4(4 \%)$ & $4(4 \%)$ & \multirow{4}{*}{0.799} \\
\hline 2 & $97(78 \%)$ & $14(11 \%)$ & $8(6 \%)$ & $5(4 \%)$ & \\
\hline 3 & $75(81 \%)$ & $6(6 \%)$ & $5(5 \%)$ & $7(8 \%)$ & \\
\hline 4 & $45(82 \%)$ & $3(5 \%)$ & $4(7 \%)$ & $3(5 \%)$ & \\
\hline \multicolumn{6}{|l|}{ Recurrence $\ddagger$} \\
\hline No Recurrence & $147(74 \%)$ & $21(11 \%)$ & $18(9 \%)$ & $14(7 \%)$ & \multirow{4}{*}{0.001} \\
\hline Local Recurrence Only & $78(89 \%)$ & $7(8 \%)$ & $1(1 \%)$ & $2(2 \%)$ & \\
\hline Nodal Recurrence Only & $39(98 \%)$ & $0(0 \%)$ & $1(3 \%)$ & $0(0 \%)$ & \\
\hline Both Nodal and Local & $31(91 \%)$ & $0(0 \%)$ & $0(0 \%)$ & $3(9 \%)$ & \\
\hline \multicolumn{6}{|l|}{ Treatment Modality } \\
\hline Radiotherapy Alone & $69(85 \%)$ & $3(4 \%)$ & $4(5 \%)$ & $5(6 \%)$ & \multirow{4}{*}{0.775} \\
\hline Surgery Alone & $119(81 \%)$ & $12(8 \%)$ & $8(5 \%)$ & $8(5 \%)$ & \\
\hline Surgery + Radiotherapy & $98(80 \%)$ & $12(10 \%)$ & $7(6 \%)$ & $5(4 \%)$ & \\
\hline Radiotherapy-> Surgery & $9(69 \%)$ & $1(8 \%)$ & $2(15 \%)$ & $1(8 \%)$ & \\
\hline \multicolumn{6}{|l|}{ Status } \\
\hline Non HNSCC death & $100(66 \%)$ & $20(13 \%)$ & $20(13 \%)$ & $11(7 \%)$ & \multirow{3}{*}{0.000} \\
\hline HNSCC death & $123(98 \%)$ & $1(1 \%)$ & $0(0 \%)$ & $2(2 \%)$ & \\
\hline Alive & $72(84 \%)$ & $7(8 \%)$ & $1(1 \%)$ & $6(7 \%)$ & \\
\hline \multicolumn{6}{|l|}{ All Cause Death } \\
\hline Yes & $223(81 \%)$ & $21(8 \%)$ & $20(7 \%)$ & $13(5 \%)$ & \multirow[b]{2}{*}{0.177} \\
\hline No & $72(84 \%)$ & $7(8 \%)$ & $1(1 \%)$ & $6(7 \%)$ & \\
\hline
\end{tabular}

Row percentages shown in braces

*P-value calculated across columns

† 2 patients missing tumor and clinical stage information

$\ddagger 1$ patient missing local recurrence information 
Citation: Farhadieh RD, Otahal P, Taghavi K, Salardini A, Russell P, Smee R (2011) Second Primary Tumours of the Head and Neck are not Associated with Adverse Overall Survival in Oral Squamous Cell Carcinomas. J Cancer Sci Ther 3: 030-034. doi:10.4172/1948-5956.1000053

Nineteen $(5.2 \%)$ developed remote-SPT. Comparison of clinicopathologic criteria of patients did not indicate any important differences across the SPT categories except for local and nodal recurrence (Table 1).

\section{SPT timing, location and effect on survival}

Comparison of median survival amongst patients indicated a superior OS of those diagnosed with a UAD-SPT (112 months from the diagnosis of the primary tumor) when compared to patients without SPT (40 months). Further analysis confirmed this to be confined to the HNSCC-SPT subset (Table 2, Figure 1). A further analysis comparing OS in patients with recurrence showed that the superior survival in HNSCC-SPT patients is not as strong in patients without a recurrence (Table 3). Cox proportional hazard regression analysis (Table 4) showed that patients with HNSCC-SPT have a mortality rate $51 \%$ less than those patients without SPT after adjustment for local and nodal recurrence. To explore the possibility that this is a selection bias the same Cox analysis was conducted on subjects that had survived for at least 24 months (Table 5). This showed that the rate of death for the

HNSCC-SPT groups is still lower than the 'No SPT' group but no longer statistically significant. The median diagnostic time delay from the onset of the index tumor to UAD-SPT was the longest for the HNSCC type. Head and neck specific survival could not be analyzed across SPT subgroups, due to lack of events in patients with SPT.

\section{Discussion}

The adverse survival prognostic effect of HNSCC-SPTs has long been accepted $[3,6,10]$. An increased incidence of other malignancies including bladder, pancreas and colorectal cancers has also been reported, but pathogenic theories have focused on UAD malignancies. [10] 'Condemned' mucosa or field cancerisation theory has been proposed as the basis of SPT development. Consistent with this overall theory, recent investigations examining the molecular basis of SPTs claim that at least a proportion of these originate from a single contiguous pre-malignant epithelial field, the so called second field tumours $[11,12]$. Studies differ widely $(2-30 \%)$ in their estimated risk of SPT development in part due to inconsistencies in patient selection or diagnostic criteria as well as generally inadequate follow up (Table

\begin{tabular}{|c|c|c|c|c|c|c|c|}
\hline \multirow{2}{*}{$\begin{array}{l}\text { Patient Groups Overall Survival } \\
\text { Comparisons }\end{array}$} & \multirow{2}{*}{$\begin{array}{l}\text { Median } \\
\text { follow up }\end{array}$} & \multicolumn{2}{|c|}{ Survival (months) } & \multicolumn{2}{|c|}{$\begin{array}{l}\text { 95\% Confidence Interval for the } \\
\text { Median Survival }\end{array}$} & \multirow[t]{2}{*}{ Wilcoxon } & \multirow[t]{2}{*}{ Log-Rank } \\
\hline & & Median & Std. Error & Lower & Upper & & \\
\hline no SPT & 31 & 40 & 5.40 & 30 & 54 & \multirow{2}{*}{$<0.001$} & \multirow{2}{*}{0.011} \\
\hline UAD SPT & 91 & 112 & 10.85 & 60 & 140 & & \\
\hline no SPT & 31 & 40 & 5.40 & 30 & 54 & \multirow{2}{*}{$<0.001$} & \multirow{2}{*}{0.002} \\
\hline HNSCC SPT & 134 & 151 & 4.55 & 78 & 188 & & \\
\hline no SPT & 31 & 40 & 5.40 & 30 & 54 & \multirow{2}{*}{0.159} & \multirow{2}{*}{0.974} \\
\hline lung/oesophagus SPT & 60 & 60 & 2.66 & 33 & 116 & & \\
\hline no SPT & 31 & 40 & 5.40 & 30 & 54 & \multirow{2}{*}{0.017} & \multirow{2}{*}{0.047} \\
\hline remote SPT & 94 & 94 & 6.92 & 46 & 171 & & \\
\hline
\end{tabular}

Table 2: Comparative overall survival of patient groups.

\begin{tabular}{|c|c|c|c|c|c|c|c|}
\hline \multicolumn{2}{|c|}{ Survival Comparisons } & \multicolumn{2}{|c|}{ Survival (months) } & \multicolumn{2}{|c|}{$\begin{array}{l}\text { 95\% Confidence Interval for the } \\
\text { Median survival }\end{array}$} & \multirow[b]{2}{*}{ Wilcoxon } & \multirow[b]{2}{*}{ Log-Rank } \\
\hline SPT & $\begin{array}{l}\text { Recurrence } \\
\text { (local and/or nodal) }\end{array}$ & Median & Std. Error & Lower & Upper & & \\
\hline no SPT & Yes & 16 & 0.93 & 14 & 22 & \multirow{2}{*}{0.006} & \multirow{2}{*}{0.013} \\
\hline HNSCC SPT & Yes & 110 & 7.49 & 41 & * & & \\
\hline no SPT & No & 109 & 6.74 & 77 & 119 & \multirow{2}{*}{0.062} & \multirow{2}{*}{0.274} \\
\hline HNSCC- PT & No & 152 & 5.67 & 78 & 197 & & \\
\hline
\end{tabular}

* not estimable (beyond the range of the data)

Table 3: Overall survival comparison for HNSCC-SPT and no SPT within all recurrence strata.

\begin{tabular}{|l|l|l|l|l|}
\hline Variable & Hazard Ratio & & \multicolumn{3}{|l|}{ 95\% Confidence Interval } \\
\hline Developed HNSCC-SPT & Lower & Upper & 0.31 & 0.78 \\
\hline Local Recurrence & 0.49 & 2.45 & 0.002 \\
\hline Nodal Recurrence & 3.23 & 0.97 & 0.001 \\
\hline
\end{tabular}

Table 4: Cox proportional hazard model for overall survival comparing patients that developed HNSCC-SPT with those that did not develop SPT.

\begin{tabular}{|l|l|l|l|l|}
\hline Variable & Hazard Ratio & \multicolumn{2}{|l|}{$\mathbf{9 5 \% \text { Confidence Interval }}$} \\
\hline Developed HNSCC-SPT & & Lower & Upper & \\
\hline Local Recurrence & 0.67 & 0.40 & 1.10 \\
\hline Nodal Recurrence & 2.77 & 1.82 & 0.113 \\
\hline
\end{tabular}

Table 5: Cox proportional hazard model for overall survival comparing patients that developed HNSCC-SPT with those that did not develop SPT (for patients surviving a minimum of 24 months). 


\begin{tabular}{|c|c|c|c|c|c|c|c|c|c|c|c|c|c|}
\hline \multirow{3}{*}{ Author } & \multirow{3}{*}{ Patient (n) } & \multirow{3}{*}{ Index Site } & \multirow{3}{*}{$\begin{array}{l}\text { Time delay } \\
\text { to SPT (Yrs) }\end{array}$} & \multirow{2}{*}{\multicolumn{2}{|c|}{ Incidence of SPT }} & \multicolumn{8}{|c|}{ Site of SPT } \\
\hline & & & & & & \multicolumn{2}{|c|}{ HNSCC-SPT } & \multicolumn{2}{|c|}{ Lung-SPT } & \multicolumn{2}{|c|}{ Oesophagus-SPT } & \multicolumn{2}{|c|}{ Remote-SPT } \\
\hline & & & & No & $\%$ & No & $\%$ & No & $\%$ & No & $\%$ & No & $\%$ \\
\hline Berg $^{13}$ & 1651 & HNSCC & - & 167 & 10.1 & 30 & 1.8 & 39 & 2.4 & 11 & 0.7 & - & - \\
\hline Boice $^{14}$ & 4139 & Larynx & $1-4$ & 541 & 13.1 & 40 & 1.0 & 178 & 4.3 & 19 & 0.5 & 139 & 3.4 \\
\hline Brown ${ }^{15}$ & 1600 & HNSCC & 5 & 61 & 3.8 & 16 & 1 & 18 & 1.1 & - & - & 17 & 1.1 \\
\hline Cohn $^{16}$ & 267 & Larynx & - & 44 & 17 & 16 & 6.0 & 10 & 3.7 & 12 & 4.5 & 10 & 3.7 \\
\hline De Viri ${ }^{18}$ & 1660 & Larynx & 5.5 & 84 & 5 & 5 & 0.3 & 25 & 1.5 & 4 & 0.2 & 52 & 3.1 \\
\hline DeVries $^{29}$ & 748 & Larynx & 4 & 104 & 14 & 9 & 1.2 & 64 & 8.6 & 0 & 0 & 31 & 4.1 \\
\hline Gluckman $^{19}$ & 5337 & HNSCC & - & 548 & 11.2 & 246 & 5.0 & 181 & 3.7 & 120 & 2.5 & - & - \\
\hline Haughey ${ }^{20}$ & 3706 & HNSCC & - & 475 & 12.8 & 246 & 6.6 & 106 & 2.9 & 17 & 0.5 & 159 & 4.3 \\
\hline Larson $^{10}$ & 875 & HNSCC & 1.5 & 207 & 23.7 & 126 & 14.4 & 54 & 6.2 & 13 & 1.5 & - & - \\
\hline Leon 6 & 1074 & Larynx & - & 169 & 15.7 & 48 & 4.5 & 66 & 6.1 & 13 & 1.2 & 39 & 3.9 \\
\hline $\operatorname{Lin}^{5}$ & 662 & Larynx & - & 51 & 7.7 & 6 & 0.9 & 31 & 4.7 & 2 & 0.3 & - & - \\
\hline Lundgren ${ }^{21}$ & 295 & Larynx & 6.3 & 32 & 10.8 & 10 & 3.4 & 12 & 4.1 & 2 & 0.7 & - & - \\
\hline Masaki²2 & 3162 & HNSCC & - & 182 & 5.8 & 66 & 2.1 & 34 & 1.1 & - & - & 18 & 0.6 \\
\hline McDonald $^{23}$ & 235 & Larynx & 4 & 50 & 21 & 9 & 3.8 & 22 & 9.4 & - & - & 16 & 6.8 \\
\hline Miyahara ${ }^{24}$ & 1389 & Larynx & $0-23$ & 138 & 9.95 & 43 & 3.1 & 23 & 1.7 & 3 & 0.2 & 68 & 4.9 \\
\hline Olsen $^{25}$ & 3847 & HNSCC & $1-4$ & 368 & 9.6 & 16 & 0.4 & 131 & 3.4 & - & - & 100 & 2.6 \\
\hline Tsou $^{4}$ & 1477 & HNSCC & 1.9 & 108 & 7.3 & 63 & 4.2 & 5 & 0.3 & 14 & 0.9 & 39 & 2.6 \\
\hline Vaamonde $^{3}$ & 636 & HNSCC & - & 48 & 7.5 & 34 & 5.3 & 7 & 1.1 & 4 & 0.6 & 3 & 0.5 \\
\hline Wagenfeld ${ }^{30}$ & 740 & Larynx & - & 48 & 6.5 & 16 & 48 & 25 & 52 & - & - & - & - \\
\hline Farhadieh $^{8}$ & 987 & Larynx & 3.5 & 143 & 14.5 & 83 & 8.4 & 56 & 5.7 & 4 & 0.41 & 65 & 6.6 \\
\hline
\end{tabular}

Table 6: Retrospective patient series examining the incidence of SPT.

6) $[3-6,8,10,13-26]$. It is generally accepted that diagnosis of the index tumour in concert with the premise of field cancerisation imparts a subsequent permanent risk of developing SPT [2-6,20,27].

In a recent series of 1257 patients (595 Oral SCCs and 662 Larynngeal SCCs) Lin et al. [5] reported a significantly better disease-specific survival, disease-free survival and a better 3-year survival trend for patients with UAD-SPTs. Further evidence from recent investigations into UAD-SPT confirms that patients afflicted with HNSCC-SPT fare better than those with SPT of other origins (pulmonary or oesophageal) [3-6]. Most recently we analysed the effects of radiotherapy in larynngeal SCCs. In a study of 987 cases we were unable to demonstrate any difference in the incidence of SPT amongst patients receiving radiotherapy or those treated with surgery alone [28]. Our analysis of incidence of SPT during follow-up broadly reflected similar outcomes reported here. There was no evidence that the HNSCC-SPT had an adverse effect on OS [8].

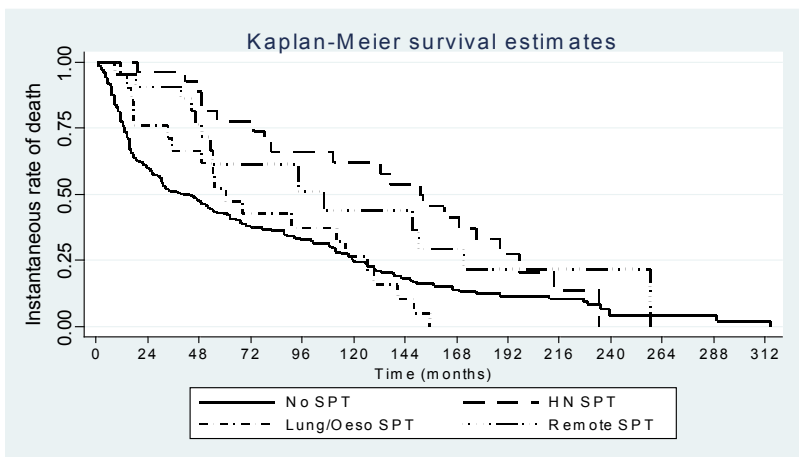

Figure 1: Kaplan-Meier all-cause survival curves for Head \& Neck SPT, Lung \& Oesophagus SPT, Remote SPT, and no SPT patient groups.
In our series we were able to show a better OS for patients diagnosed with HNSCC-SPT during follow-up when compared to patients not diagnosed with SPTs or those diagnosed with lung/oesophageal SPT. This latter comparison marks the clearly well established poor survival prognosis of these (lung/oesophageal SPTs) malignancies and our results are consistent with those of other series $[6,10]$. The apparent survival superiority of HNSCC-SPT patients is at odds with most previous studies.

Any longitudinal investigation of this nature is inevitably tainted to some degree by survivorship bias e.g. patients with 'worst' primary tumours will succumb to these and will be inadvertently overlooked because of their lack of visibility. Specifically in this study, median follow-up for patients with no SPT was short (31 months), and given the risk of SPTs is assumed constant, many of these patients would have developed an SPT later on (after 31 months).

This concept can explain why the patients that did not develop SPT had markedly higher rates of recurrence (local and/or nodal) as compared with the HNSCC-SPT group. Added to this, autopsy was not performed in every patient who died, therefore there will be even more SPT in this group that could be overlooked. Only with adequate and substantial follow-up, can the constant and accumulating development of SPT be appreciated.

Nevertheless, a separate analysis conducted for subjects with no recurrence shows that this superior survival of HNSCC-SPT patients persists. However, there may potentially be other unmeasured confounding variables that act to elevate the rate of death in patients who do not develop SPT. The less significant impact of HNSCC-SPT on OS is related to the relatively innocuous prognosis of HNSCCs when compared with lung or esophageal malignancies. The initial better survival shown by patients who develop HNSCC-SPT is tempered by an increase in mortality rate beyond 96 months. Figure 2 show 


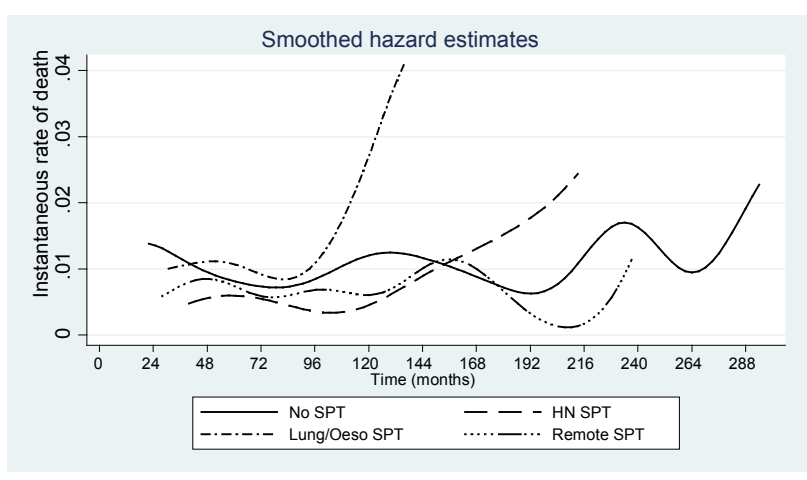

Figure 2: The rate of death with time for Head and Neck SPT, Lung and Oesophagus SPT, and Remote SPT groups and the no-SPT group.

that after 200 months, there are little differences in survival between HNSCC-SPT patients and patients without SPT (however few patients remain at risk to infer a clear conclusion). An area with huge potential for development and research is the molecular study of second field tumors and single contiguous pre-malignant epithelial fields and how these influence local recurrences, SPTs and prognosis.

\section{Conclusion}

In light of this series, we believe that UAD-SPT should be clinically divided into the HNSCC-SPT and non-HN subsets for classification purposes. This would have a significant bearing on the perceived overall prognosis of patients.

\section{References}

1. Pisani P, Bray F, Parkin DM (2002) Estimates of the world-wide prevalence of cancer for 25 sites in the adult population. Int J Cancer 97: 72-81.

2. Tepperman BS, Fitzpatrick PJ (1981) Second respiratory and upper digestive tract cancers after oral cancer. Lancet 2: 547-549.

3. Vaamonde P, Martín C, del Río M, LaBella T (2003) Second primary malignancies in patients with cancer of the head and neck. Otolaryngol Head Neck Surg 129: 65-70.

4. Tsou YA, Hua CH, Tseng HC, Lin MH, Tsai MH (2007) Survival study and treatment strategy for second primary malignancies in patients with head and neck squamous cell carcinoma and nasopharyngeal carcinoma. Acta Otolaryngol 127: 651-657.

5. Lin K, Patel SG, Chu PY, Matsuo JM, Singh B, et al. (2005) Second primary malignancy of the aerodigestive tract in patients treated for cancer of the oral cavity and larynx. Head Neck 27: 1042-1048.

6. León X, Quer M, Diez S, Orús C, López-Pousa A, et al. (1999) Second neoplasm in patients with head and neck cancer. Head Neck 21: 204-210.

7. Slaughter Dp, Southwick Hw, Smejkal W (1953) Field cancerization in oral stratified squamous epithelium; clinical implications of multicentric origin. Cancer 6: 963-968

8. Farhadieh RD, Salardini A, Yang JL, Russell P, Smee R (2010) Diagnosis of second head and neck tumors in primary laryngeal SCC is an indicator of overall survival and not associated with poorer overall survival: a single centre study in 987 patients. J Surg Oncol 101: 72-77.

9. Warren S, Gates O (1932) Multiple primary malignant tumours: A survey of the literature and a statistical study. Am J Cancer 15: 1348-1414.
10. Larson JT, Adams GL, Fattah HA (1990) Survival statistics for multiple primaries in head and neck cancer. Otolaryngol Head Neck Surg 103: 14-24.

11. Tabor MP, Brakenhoff RH, Ruijter-Schippers HJ, Van Der Wal JE, Snow GB et al. (2002) Multiple head and neck tumors frequently originate from a single preneoplastic lesion. Am J Pathol 161: 1051-1060.

12. Braakhuis BJ, Brakenhoff RH, Leemans CR (2005) Second field tumors: a new opportunity for cancer prevention? Oncologist 10: 493-500.

13. Berg JW, Schottenfeld D, Ritter F (1970) Incidence of multiple primary cancers III. Cancers of the respiratory and upper digestive system as multiple primary cancers. J Natl Cancer Inst 44: 263-274.

14. Boice JD Jr, Fraumeni JF Jr (1985) Second cancer following cancer of the respiratory system in Connecticut, 1935-1982. Natl Cancer Inst Monogr 66: 83-98.

15. Brown M (1978) Second primaries in cases of cancer of the larynx. J Laryngo Otol 92: 991-996.

16. Cohn AM, Peppard SB (1980) Multiple primary malignant tumors of the head and neck. Am J Otolaryngol 1: 411-417.

17. de Vries N, Van der Waal I, Snow GB (1986) Multiple primary tumours in ora cancer. Int J Oral Maxillofac Surg 15: 85-87.

18. Deviri E, Bartal A, Goldsher M, Eliachar I, Steinitz R, et al. (1982) Occurrence of additional primary neoplasms in patients with laryngeal carcinoma in Israe (1960-1976). Ann Otol Rhinol Laryngol 91: 261-265.

19. Gluckman JL, Crissman JD (1983) Survival rates in 548 patients with multiple neoplasms of the upper aerodigestive tract. Laryngoscope 93: 71-74.

20. Haughey BH, Gates GA, Arfken CL, Harvey J (1992) Meta-analysis of second malignant tumors in head and neck cancer: the case for an endoscopic screening protocol. Ann Otol Rhinol Laryngol 101: 105-112.

21. Lundgren J, Olofsson $\mathrm{J}$ (1986) Multiple primary malignancies in patients treated for laryngeal carcinoma. J Otolaryngol 15: 145-150.

22. Masaki N, Hashimoto T, Ikeda H, Inoue T, Kozuka T (1987) Multiple primary malignancies in patients with head and neck cancer. Jpn J Clin Oncol 17: 303 307.

23. McDonald S, Haie C, Rubin P, Nelson D, Divers LD (1989) Second malignan tumors in patients with laryngeal carcinoma: diagnosis, treatment, and prevention. Int J Radiat Oncol Biol Phys 17: 457-465.

24. Miyahara H, Sato T, Yoshino K (1998) Radiation-induced cancers of the head and neck region. Acta Otolaryngol Suppl 533: 60-64.

25. Olsen JH (1985) Second cancer following cancer of the respiratory system in Denmark, 1943-80. Natl Cancer Inst Monogr 68: 309-324.

26. Wagenfeld DJ, Harwood AR, Bryce DP, van Nostrand AW, DeBoer G (1980) Second primary respiratory tract malignancies in glottic carcinoma. Cancer 46 1883-1886.

27. Gao X, Fisher SG, Mohideen N, Emami B (2003) Second primary cancers in patients with laryngeal cancer: a population-based study. Int J Radiat Oncol Biol Phys 56: 427-435.

28. Farhadieh RD, Rees CG, Yang JL, Salardini A, Russell P, et al. (2009) Radiotherapy in larynx squamous cell carcinoma is not associated with an increased diagnosis of second primary tumours. Clin Oncol (R Coll Radiol) 21 : 315-319.

29. de Vries N, Snow GB (1986) Multiple primary tumours in laryngeal cancer. $J$ Laryngol Otol 100: 915-918.

30. Wagenfeld DJ, Harwood AR, Bryce DP, van Nostrand AW, de Boer G (1981) Second primary respiratory tract malignant neoplasms in supraglottic carcinoma. Arch Otolaryngol 107: 135-137. 